\title{
طب وجراحة الأورام في الحضارة الإسلامية
}

عبد الله سالم بازينة

كلية الاداب جامعة مصراتة
خيرية مصطفى السيوي1

كلية الاداب جامعة مصراتة

محمد أحمد الفقيه

المعهد القومي للأورام مصراتة

تاريخ التقديم: 11-10-2021، تاريخ القبول: 22-11- 2021، نشر إلكترونيا في 23-11-2021 https://doi.org/10.36602/faj/2021.n.18.12

\section{ملخص البحث:}

الأورام هي نوع من الأمراض الشائعة أو المزمنة التي واجهت الإنسان منذ القدم، حيث القدان

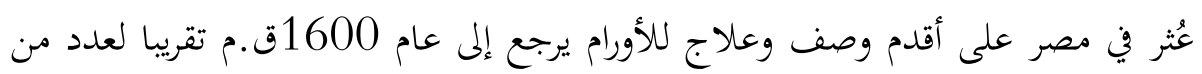

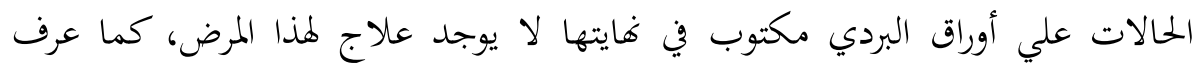

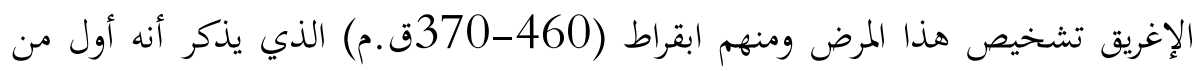

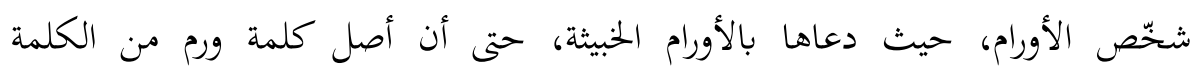
(onklogic) يطلق على دراسته علم الأورام، وبعد حركة الترجمة والنقل التي شهدةا الخلافة الإسلامية في إنماني

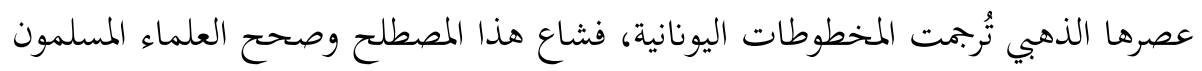
الكثير من المفاهيم المغلوطة في الطب وقدموا الشروح الكثيرة والكتب في هذا المجال، حيث لمثيخ

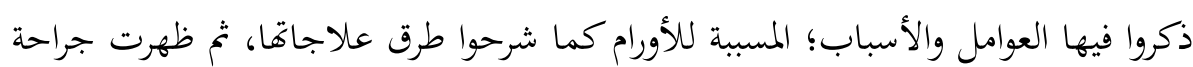
استئصال الأورام واخترعوا كثيراً من الآلات الجراحية. الكلمات المفتاحية: الأورام، السرطان، الحضارة الإسلامية، الطب.

Kh.alsiwi@art.misuratau.edu.ly ${ }^{1}$ 


\title{
Oncology Treatment in Islamic Civilization
}

\section{Khayriyah Mustafa Al Siwi}

Abdullah Salem Bazina

Faculty of Arts, Misurata University

\section{Mohamed Ahmed Al-Faqih}

National Cancer Institute Misurata

\begin{abstract}
Tumors are a type of common or chronic diseases that have confronted man since ancient times. The oldest description and treatment of tumors were found in Egypt, dating back to the year 1600 $\mathrm{BC}$. $\mathrm{AD}$, for a number of cases on papyrus written at the end of which "there is no cure for this disease", as the Greeks knew the diagnosis of this Disease, including Hippocrates (460-370 BC), who mentions that he was the first to diagnose tumors, calling them malignant tumors, so that the word tumor comes from the word (onklogic) from the Greek language (onkos), which means tumor, size or mass, so it is called His study of oncology, and after the movement of translation and transmission that the Islamic Caliphate witnessed in its golden age, the Greek manuscripts were translated. Then there was surgery to remove tumors and they invented many surgical instruments.
\end{abstract}

Keywords: tumors, cancer, Islamic civilization, medicine.

$$
\begin{aligned}
& \text { 1 } 1 \\
& \text { كان مرض السرطان ولا يزال موضوعاً مثاراً للدراسة والنقاش، فهو من أخطر } \\
& \text { الأمراض التي عرفها الإنسان، إلا أن الاختلاف والجدال كان في فترة ظهور الورم، فمنهم } \\
& \text { من يقول عرف في فترة ما قبل الميلاد، والبعض الآخر يرى أن اكتشافه كان بتطور الطب }
\end{aligned}
$$


في عصر الحضارة الإسلامية، حيث كان للأطباء المسلمين دوراً بارزاً في تطوره، فظهر العديد من الأطباء المسلمين المتخصصين في هذا الجانب من الطب، ومع مرور الزمن تطورت طرق علاجه وكيفية الحد من انتشاره، بالحث على بجموعة من النصائح الصحية واتباعها، ولقد سجل تاريخ الحضارة الإنسانية دور العلماء المسلمين الأوائل في مختلف ضروب الثقافة والعلوم، وبفضل الترجمة من اللغات الأجنبية خاصة من اليونانية والفارسية والهندية إلى العربية، نضجت ملكات المسلمين في البحث والتأليف واتسع أفق الفكر الإسلامي بارتحال المسلمين في مشارق الأرض ومغاربها، بعكس أوروبا التي كانت تعيش في ظلام العصور الوسطى وتقع تحت سيطرة الكنيسة، التي كانت ترى أها المسؤولة على شفاء الأمراض، وكانت تنظر بعين الاحتقار إلى كل من يمارس مهنة الطب باليد، حتى جس النبض اعتبر أمراً مهيناً، وحرّمت على رجالها ممارسته "وأنه لمشين حقاً أن يعمل الطبيب بيديه" (هونكه، 1990، ص ص219-220)، ولا أدل على تخلف الطب في أوروبا؛ إصدار الملك (ثيودور) أحد ملوك القوط الغربيين أمراً: "أنه إذا توفي المريض نتيجة لعملية جراحية، فإن الطبيب الذي أجرى العملية يسلم لأهل المتوفن ، ولمم الحرية ليفعلوا به ما

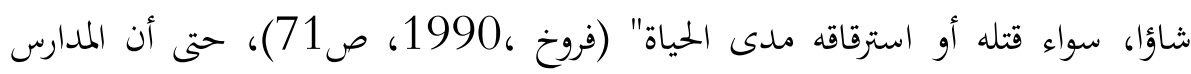
الطبية كانت تخشي ممارسة تعليم الجراحة وينظرون إليها بكل احتقار، ولأها لا تليق بالأطباء المحترمين أصدر مجلس تورس البابوي قراراً يوجب على المدارس الطبية أن يهملوا تعليم الجراحة (طوقان، د.ت، ص25)، وبينما هذه الحال في أوروبا من اعتبار الجراحة من الأمور غير المقبولة أو المسموح بها وكان الإقبال على الجراحة في أوروبا محدوداً جداً؛ كان التنافس العلمي على أشده بين الأطباء المسلمين، وظهر الأطباء الجراحون المرموقون في العالم الإسلامي (حلاق ، 1990، ص40). 
وتكمن اشكالية الدراسة في سؤالها الرئيسي وهو:

ما قدم مصطلح الأورام؟ وهل كان شائعاً عند الأطباء المسلمين؟ وما مدى مساهمة الحضارة الاسلامية في طب وجراحة الأورام؟ 1

- ما هو مصطلح الأورام؟ وهل استعمل هذا المصطلح في الحضارة الإسلامية أم ظهر حديثاً؟

- من هم أبرز الأطباء المسلمين في هذا المجال؟ - ما هو دور الطب والجراحة في القضاء على الورج؟

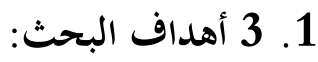
- التعرف على الجذور التاريخية لظهور مصطلح الأورام. - تحديد العصر الإسلامي لتطور ودراسة هذا المرض. - معرفة الطرق العلاجية التي اتبعها الأطباء في معالجة الأورام. - بيان دور الأطباء المسلمين وما قدموا من إسهامات كبيرة في تاريخ الطب عامة والجراحة خاصة وابتكارهم للعديد من الآلات والأدوات الجراحية وطرق استعمال كل واحدة منها، وإجراءهم العمليات الجراحية الناجحة في مختلفة أجزاء الجسم ما يدل على خبرقم الطبية الواسعة في علم الجراحة. 
- إبراز دور الطبيب المسلم كجراح لما تركه لنا من مآثر طبية ساهمت بشكل أو بآخر في ازدهار هذا العلم في العالم الإسلامي، وإلى أي مدى استفادت أوروبا من آر ومؤلفات العلماء المسلمين. 4.1 تكمن أهمية الموضوع: في كون الطب مظهراً من مظاهر الحضارة الإنسانية التي يجب الاهتمام به ودراسته وأنه من المهن الإنسانية التي لها دور كبير في استمرار حياة البشر، وتبين دور الأطباء المسلمين وما قدموه من جهود جبارة في هذا الجانب الحضاري، وإعطاء فكرة عن دورهم الذي ساهم بشكل كبير في ازدهار الطب بصفة عامة والجراحة بصفة خاصة، فموضوع الطب في طبيعته شيق له أهمية ورونق خاص يشدّ انتباه كل باحث.

كما تكمن أهمية البحث في كونه يسلط الضوء على اشكالية يعاني منها بجتمعنا في الوقت الحالي من كثرة انتشار الأورام السرطانية، فهي محاولة لبحث في التاريخ الإسلامي عن جذور هذا المرض ومدى اسهامات الأطباء المسلمين في طب وجراحة الأورام، وما تركوا لنا من آثار حميدة وجليلة في هذا العلم، وخاصة الجراحة ودورها في القضاء على الورم.

\section{2. - 2. المنهج والإجراءات: 1.2}

تنتهج هذه الدراسة: المنهج التاريخي الذي يعتمد على جمع النصوص من المصادر

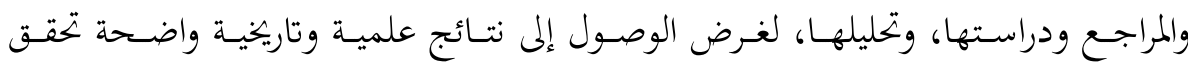
الأهداف المرجوة من الدراسة.

قسم البحث إلى مقدمة وتمهيد، وثلاثة مباحث وخاتمة، وقائمة المصادر والمراجع. 
2.2 عرض مبسط لخطة البحث، التمهيد:

ويتضمن بعض التعريفات لعلم الطب، ثم نبذة مختصرة عن بدايات الطب عند

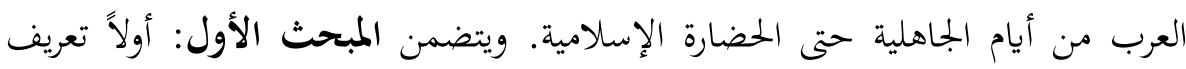

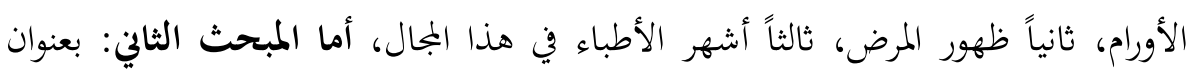
العوامل والأسباب المؤدية إلى انتشار الأورام في رأي الأطباء المسلمين، ومقسم إلى: أولاً العوامل، ثانياً الأسباب، والمبحث الثالث: عنوانه طرق علاجه في الحضارة الإسلامية، ثم الخاتمة للوصول إلى أهم نتائج الدراسة وقائمة المصادر والمراجع.

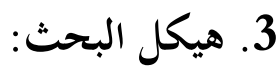

منذ أن وجد الإنسان على وجه الأرض وجدت معه الرغبة في العلاج والتخلص

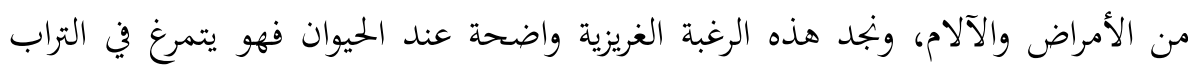
للتخلص من الحشرات، كما يلعق جروحه عند اصابته، ولا نعرف بدقة متى وأين نشأ الطب على وجه الدقة، فهو وليد بيئات وأقاليم مختلفة، وهو يعد من أشرف العلوم وأشدها بـاتها

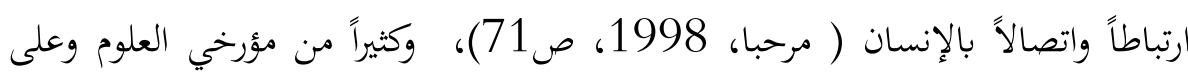

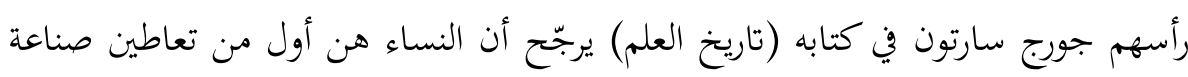

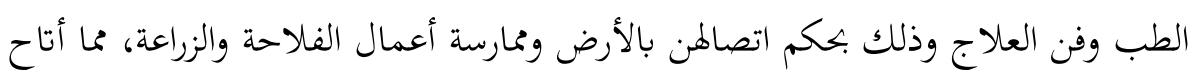
لهن علماً أوسع بالنبات، كما كن يتقن مهنة وفن التوليد أقدم المهن الطبية على الإطلاق

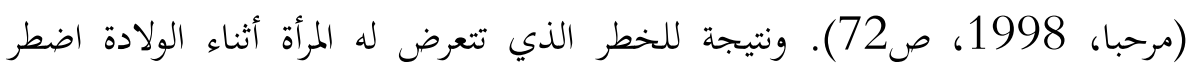

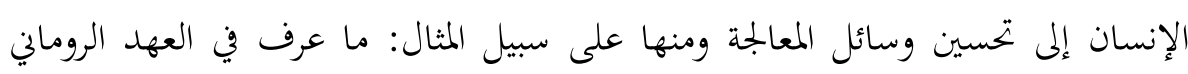

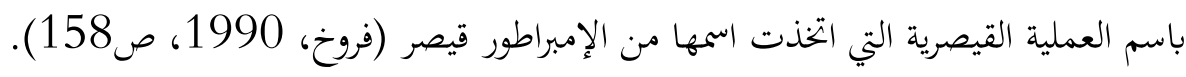


وكان لليونانيين خبرة طويلة وكبيرة بالطب، شاع ذكر أطباء منهم (اسقليبيوس) فهو أول من اعتنى بالطب عن طريق التجربة، و(ابقراط)(1) المعلم السابع، رتّب الطب وبناه

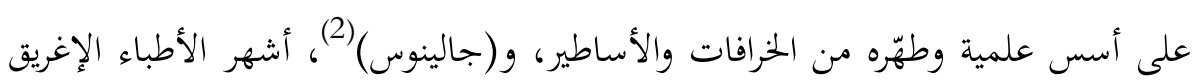

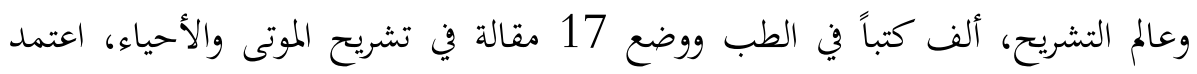

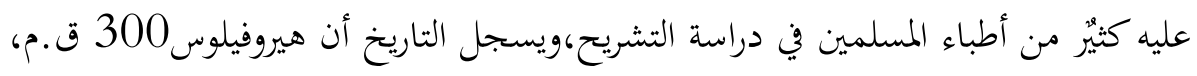

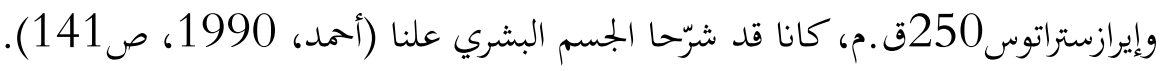
ويمكن القول عن الطب في فترة الحضارة الاسلامية بأنه: مجموعة الآراء العلمية الطبية التي كتبها الأطباء المسلمون والمستوحاة من الطب اليوناني (موراني، 1974، ص58). كما أنه علم نظري وعملي، لما فيه من حفظ الصحة ودفع العلل والأمراض (حلاق، 1989، ص797)، فالطب من العلوم المطلوبة في كل زمان ومكان لما له من صلة في حياة الإنسان (جواد، 1989، ص380). فالجسم البشري يتعرض للأمراض

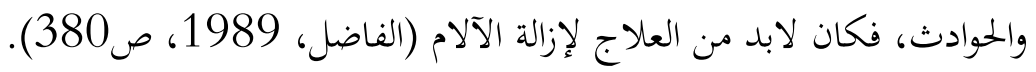
وعرف العرب الطب من أيام الجاهلية عندما خالطوا الروم والفرس وأخذوا بعض معارفهم الطبية (ابن أبي أصيبعة، 1981، صركب من 110)، فمنهم النضر بن الحارث بن كلدة

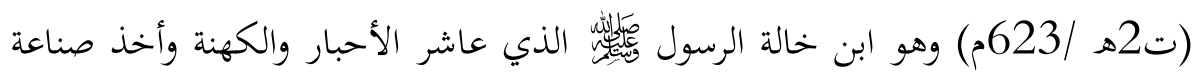
الطب عن أبيه وعن غيره (الشطشاط، 1995، صدو 99)، وأيضاً الحارث بن كلدة الثقفي

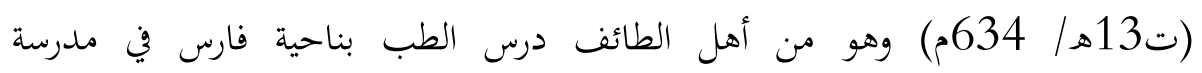

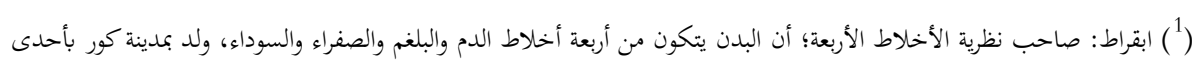

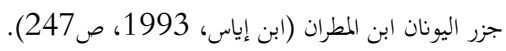

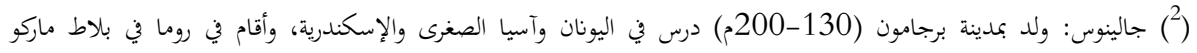

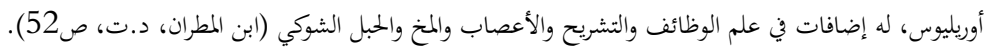


جنديسابور(1)، ونال عيادة كسرى الفرس (انوشروان) (أحمد، 1990، ص143)، وقد تخصص (الحارث) في علم الصحة وأوصى بعدم الإفراط في الطعام، كما أوصى بالحجامة،

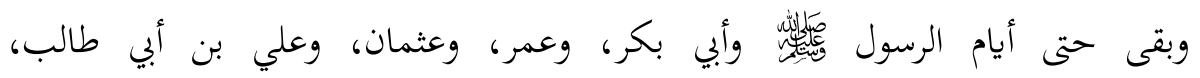
ومعاوية نِيلِئنَّ (الأندلسي، 1985، ص126)، ويذكر ابن أبي أصبيعة أن الرسول"

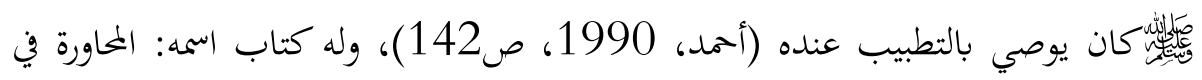
الطب (ابن أبي أصيبعة، 1981، صئس 111)، وتتحدث المصادر كذلك عن بعض النسوة ممن مارسن الطب في الجاهلية وأدركن الإسلام وقمن بدور بارز في مداواة المرضى ووقف النزيف أثناء غزوات الرسول"صلى الله عليه وسلم" عُرفن بالآسيات، يقمْنَ بمواساة الجرحى والتخفيف عنهم (أحمد، 1990، ص144)، ومن أشهرهن: الشفاء بنت عبدالله (2)، حيث سمح لها الرسول" صلى الله عليه وسلم" بمزاولة عملها بعد إسلامها (كشريد، د.ت،

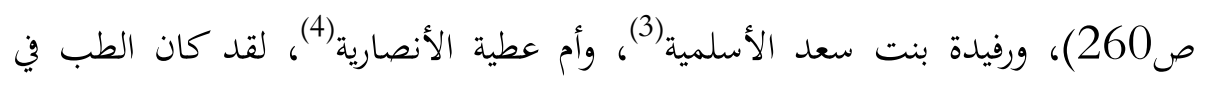
صدر الإسلام يدور في الأكثر على الوقاية من الأمراض واختيار الأطعمة النافعة، وأصول عيادة المرضى ولزوم استشارة الأطباء (الشطي، 1956، ص135)، ويمكن القول بأن الطب في صدر الإسلام هو "الطب النبوي" وهو مجموعة من الأحاديث النبوية، يبلغ عددها ثلاثمائة حديث، وتحتوي على النصائح الهامة كالحث على المداواة (أحمد، 1990، ص145)، ومعرفة الناس بشؤون دنياهم في هذا المجال واتخاذ الأساليب العلمية في فهمه،

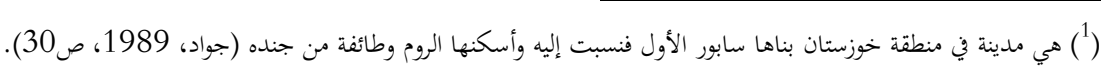

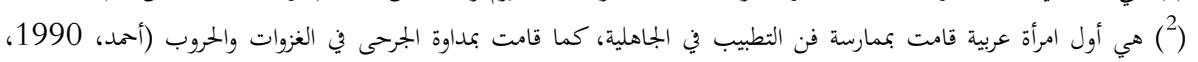

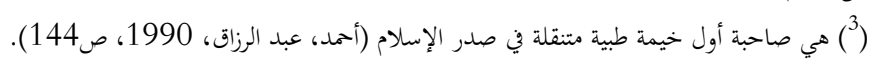

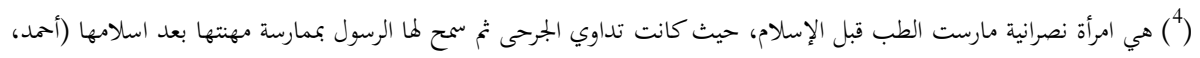

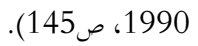


أكثر منها ديناً ووحياً، في ضوء وجود المتخصصين من الأطباء (الهواري، 2005، ص192)، وأن ما ورد من مبادئ صحية وغذائية أخذت بها النظريات العلمية الحديثة، ونهاء

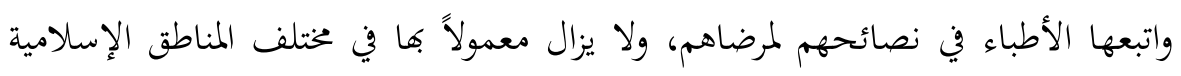

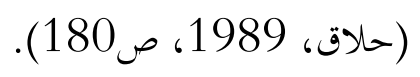

أما في عصر الدولة الاموية فإن أول من عنى بنقل الطب هو "خالد بن يزيد بن

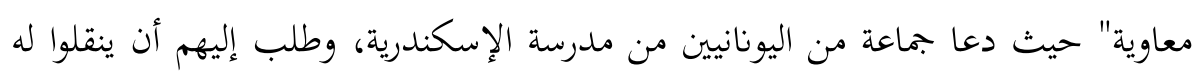

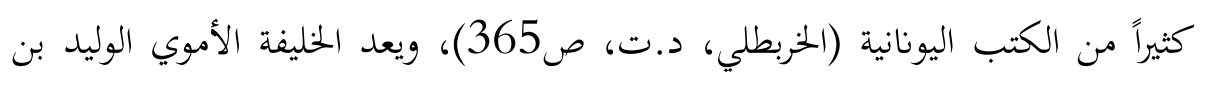

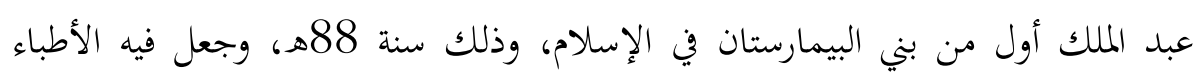

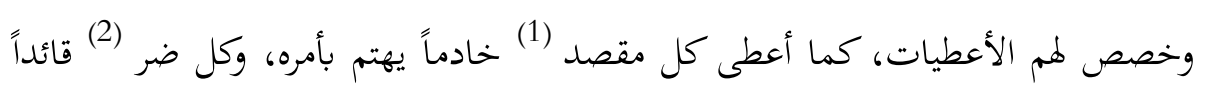

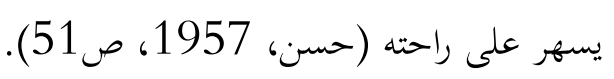
وفي عصر الخلافة العباسية، انتشرت الكتب الطبية وكثرت مراكز المعالجة وكثرة

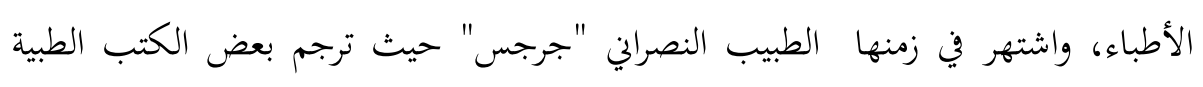

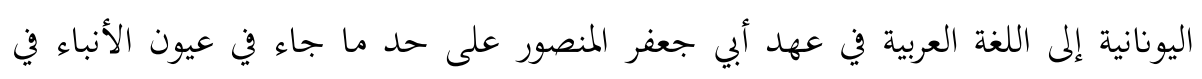

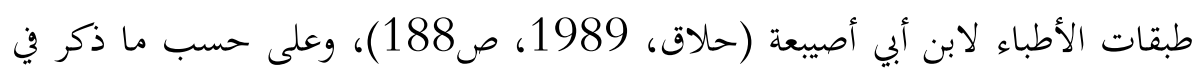

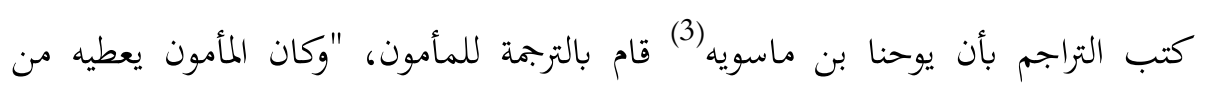

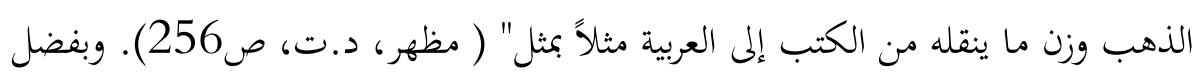

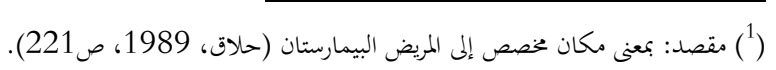

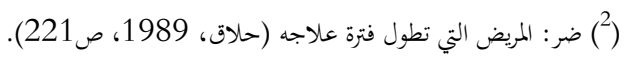

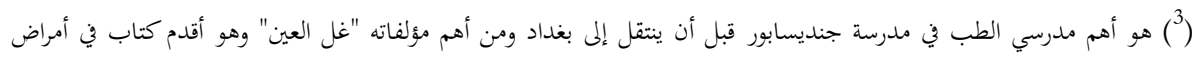

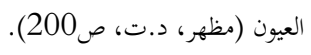


ذلك وضع أسس التعاليم الطبية، وأسس المسلمون البيمارستانات(1) لتخريج الأطباء

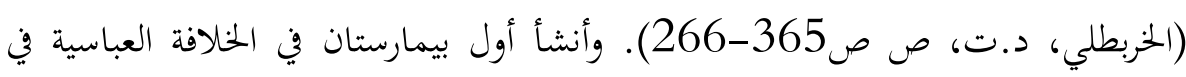
عهد هارون الرشيد ببغداد في فاية القرن الثامن الميلادي، ثم أخذت تنتشر في مطلع القرن العاشر (الخازن، 1992، صهان 120)، ويشار بمصطلح الطب الإسلامي إلى الطب الذي تطور في العصر الذهبي للإسلام في عصر الخلافة العباسية وكتب بلغة عربية، والتي كانت

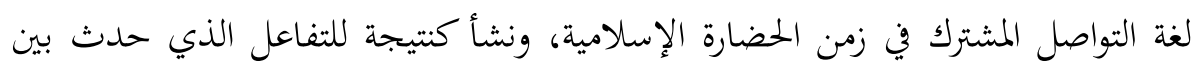

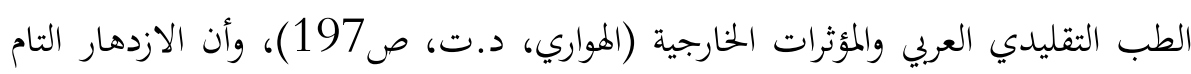

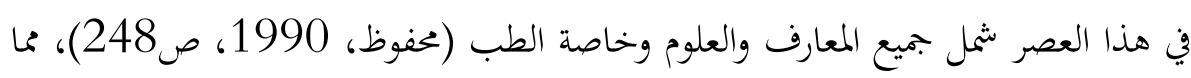

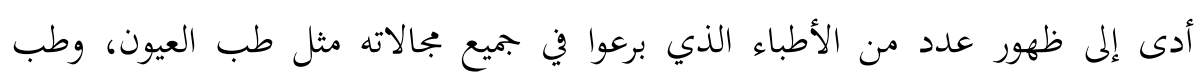
الأطفال، وطب العظام، وطب الأوبئة، وطب الأورام.

والأورام هي نوع من الأمراض الخطيرة التي واجهت الإنسان منذ القدم، إلا أن هناك اختلاف حول ظهور هذا المرض، فمنهم من يقول بأنه موجود من قبل الميلاد

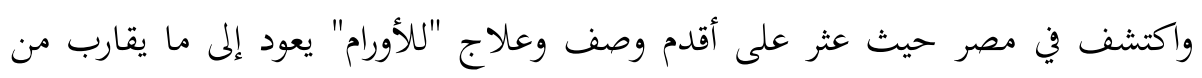

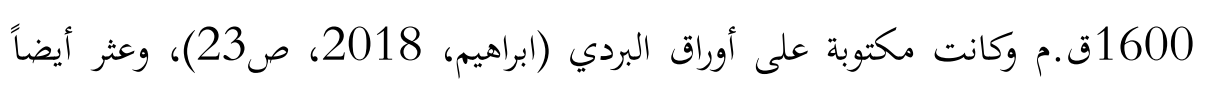

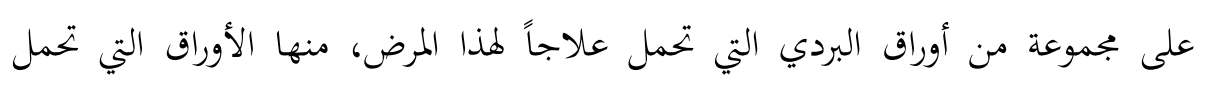

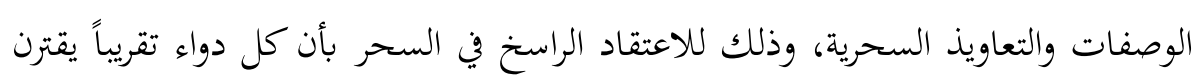

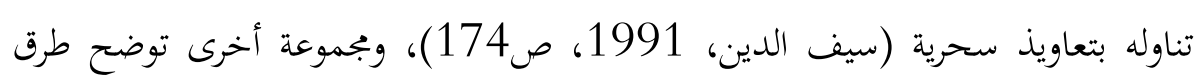

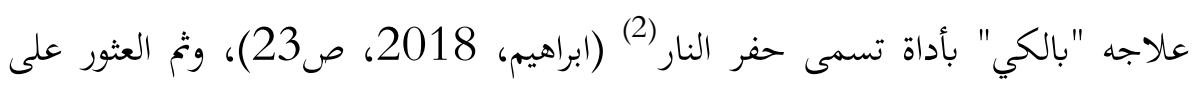
(1) حديثاً بععنى الكليات والمعاهد العملية، وهو لفظ فارسي ذا البيمار، مسكنة المرض وشأن موضع المرطب (الخربطلي، د.ت،

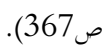
(2) هي أداة تشبه المسمار تصنع من الحديد وتوضع على النار ثم تستعمل في مكان الورم. 
ورقة البردي مكتوب عليها بأنه "لا يوجد علاج (1) لهذا المرض"، ويذكر أن أول من شخّص

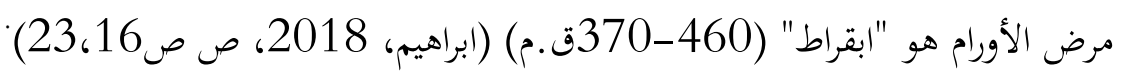

1.3 تعريف مصطلح الأورام وظهوره في الحضارة الإسلامية: 1.1.3

يمثل طب الأورم أحد فروع الطب التي تعني بالسرطان، وتأي أصل الكلمة من (onklogic) (logos) ص5،3،)، ويقول البعض أن أصل التسمية هي نتيجة تورّم منطقة معينة في جسم الإنسان

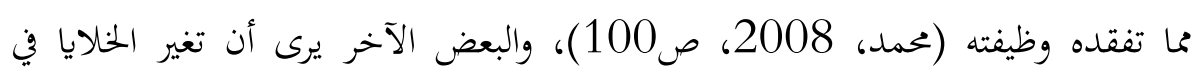

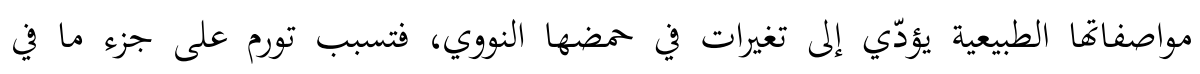

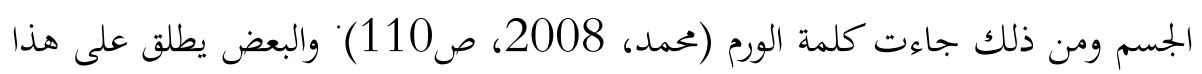

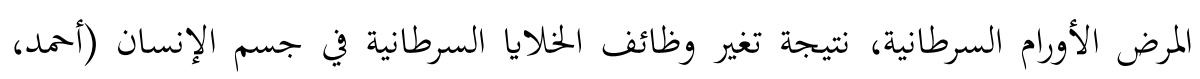

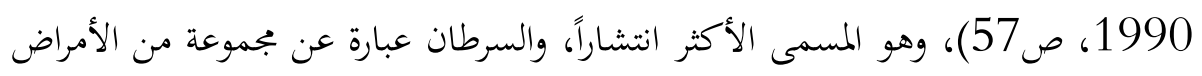

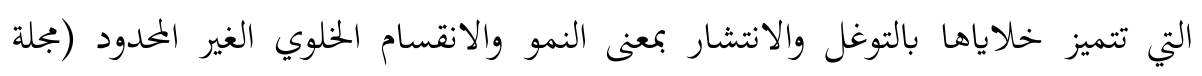

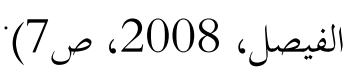
2.1.3

في عصر الخلافة العباسية استعمل مصطلح الأورام (حلاق، 1989، صدون)، وذلك في عهد المأمون حينما أمر بجمع المخطوطات اليونانية القديمة من كل مكان وأرسل (1) بالفعل فإن أغلب الأطباء حديثاً لم يتوصلو إلى علاج شفائي لهذا المرض. 
إلى بلاد الروم جماعة من علمائه منهم الحجاج بن مطر، وابن البطريق فأخذوا ما وقع عليه اختيارهم من كتب اليونان القديمة، التي كانت مهملة في بلاد الروم ولا ينتفع بها أحد ونقلوها إلى بغداد (مظهر، د.ت، ص256)، وبعد حركة الترجمة من اليونانية إلى العربية أثبت أن جالينوس تحدث عن الأورام وأطلق عليها الأورام الحميدة، وأما ابقراط دعاها الأورام الحبيثة، وكان ذلك من قبل المترجمين في القرن الثاني الميلادي (الرافعي، 1988، ص292)، ويذكر ابن أبي أصيبعة أن من المخطوطات اليونانية التي نقلت إلى بغداد هي خخطوطة آيا صوفيا(1) التي تقول عن الورم: "إنّ الورم الذي لا يرشح منه شيء هو مركب ولا يعلمون أن الورم إذا حدث في عضو متخلخل أيضاً بمنزلة العين، إن كانت مادته رقيقة، رشح وجرى منه بعضها، وإن كانت غليظة لم ترشح شيء منها" (ابن أبي أصيبعة، 1981، ص137)، وهذا ما يثبت أن مصطلح الأورام قد استعمل فعلاً في عصر الخلافة العباسية نتيجة حركة التربمة والنقل، ففي هذا العصر صحح الكثير من المفاهيم المغلوطة في الطب، فضلاً عن ما قدموه من الشروح الكثيرة في هذا المجال (محمد، 1991، ص137)، ولعل السبب الذي جعل الأطباء في فترة الخلافة العباسية يهتموا بالأورام هو الترف الذي حصل في هذا العصر، وتنوع الطعام والشراب فتعرضت الأجسام لعدة أمراض فاحتاج المسلمون لدراسة الطب (فروخ، 1990، ص78)، وقد اقتبس العباسيون الطب من الفرس والهنود، ومن ثم ظهرت مهاراتم في الجراحة وصناعة العقاقير وتركيبها (الهواري، 2005، ص 59). (59). 


\subsection{3 أشهر الأطباء في هذا الجحال:}

يعتبر (الزهراوي)(1) أول طبيب مسلم كان له أسلوبه في معالجة التورمات

السرطانية الخبيثة (سليمان، 1990، ص153)، وهو من أعطى لهذا المرض وصفاً وعلامات تستعمل إلى اليوم وقد أشار إليه في كتابه "التصريف لمن عجز عن التأليف" (حلاق، 1989، ص151) الذي اكتمل في فاية القرن العاشر، وقد نقل معلومات عنه "الحميدي" ومؤلفو تراجم لاحقون أمثال (ابن أبي أصبيعة) دون إضافة أية معلومات هامة (محفوظ، 1990، ص96)، ويعتبر الزهراوي أستاذ أطباء أوروبا بواسطة كتابه " المترجم" لمدة خمسة قرون، حيث تأثر العديد من الأطباء بما جاء في كتابه الذي ساعدهم على وضع

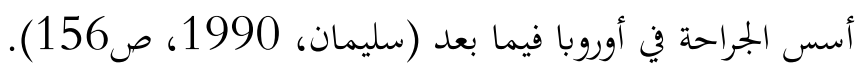

ويعتبر كتاب التصريف دائرة معارف طبية كبيرة وذلك أنه يضم أقساماً ثلاثة :

قسم في الطب وقسم في الصيدلة والقسم الثالث في الجراحة وهذه الأقسام مقسمة إلى ثلاثين مقالة (العمري، 1990، ص94) ، والمقالة الثلاثون اشتهرت في الجراحة وهي مقالة من ثلاث أبواب وتضم في مجموعها 188 فصلاً، وما يقرب من مائتي صورة توضيحية للآلات الجراحية (الطبي، 1986، ص91-92) لقد شح الزهراوي فن العمليات الجراحية ووصف آلاتما وخاصة جراحة الأورام ومن ذلك ما ذكره عن تورم الرحم فيقول الزهراوي في ذلك:"طريقة الشق على هذا الورم وعلاجه بالجراحة، ونصح بعدم إجراء العملية الجراحية إلا بعد نضوج الورم وتحله" (الشطشاط، 1995، ج2، ص 522)

(1) هو أبو القاسم خلف بن عباس الزهراوي (1990هـ 1940، 1013). 
(plvnging ranvla) وفي طب وجراحة أورام الفم فعن ورم الضفدع المتولد تحت اللسان يصف طريقة إجراء العملية الجراحية على هذا الورم بقوله:

"أن تفتح فم العليل بإزاء الشمس وتنظر إلى الورم فإن رأيته كمد اللون أو أسود صلباً

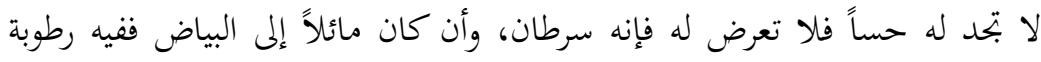

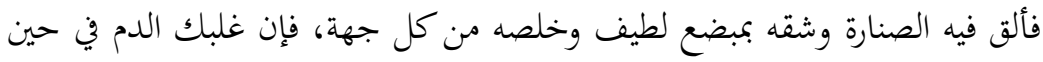

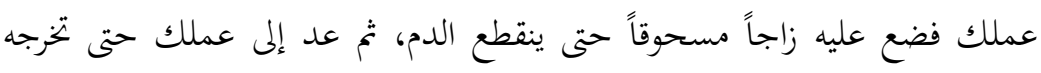

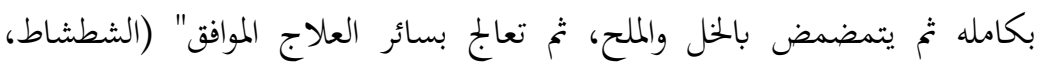

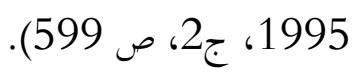

أما عن سرطان الأنف وبواسيره ونواصيره فقد تطرق الزهراوي لعلاج ناصور الأنف ويرى أنه إذ عولج بالكي أو الدواء المحرق ولم يفد ذلك فيجب إجراء العملية الجراحية

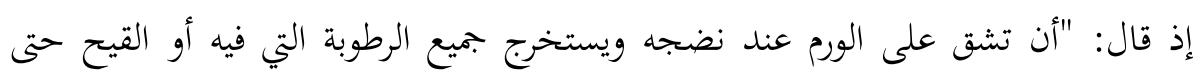

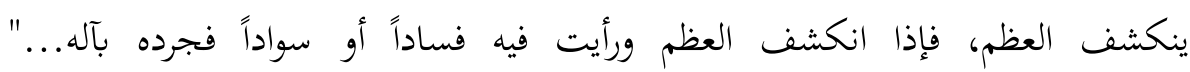

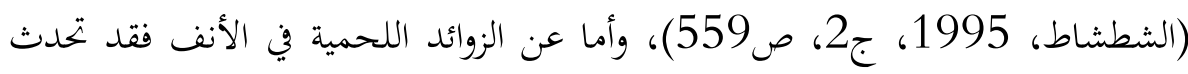
الزهراوي عن ذلك فيذكر: قد تثبت في الأنف لحوم خختلفة زائدة منها شيء يشبه العقربان

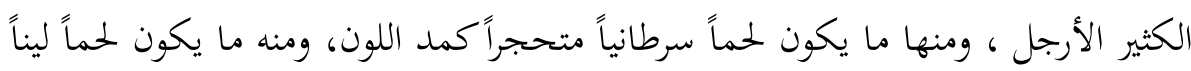

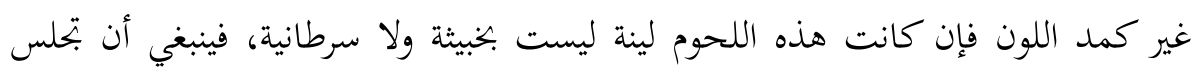
العليل بين يديك مستقبل الشمس وتفتح منخرة وتلقي الصنارة في تلك اللحوم، ثم تجذهما

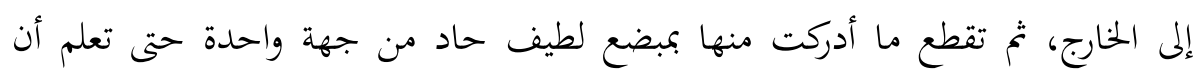

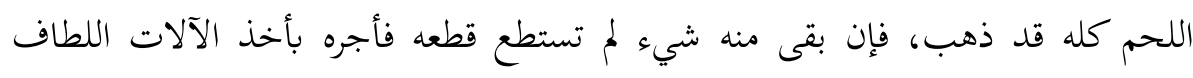

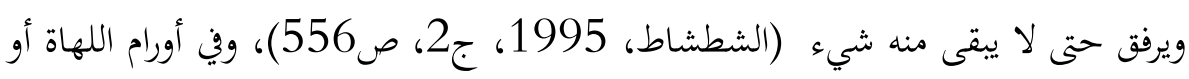
الأورام الليفية، فقد ذكر الزهراوي أن أوام اللهاة يكون على ثلاثة أنواع: "إما أن يتورم 
رأسها فيسمى ورماً عينياً وإما أن يتورم أسفلها فيسمى ورماً صلباً، وإما ما أن يتورم بكليتها

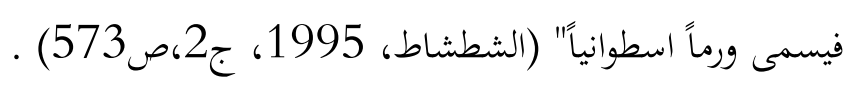

أما (ابن سينا) (980-1037) وهو أول من نصح الجراحين بعالجة أورام

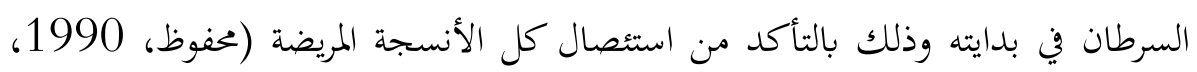

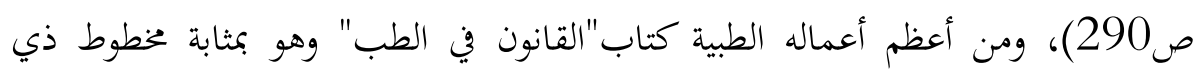
مليون كلمة، ولقد تقبل العالم الطبي الإسلامي القانون كمرجع وحيد حتى القرن التاسع

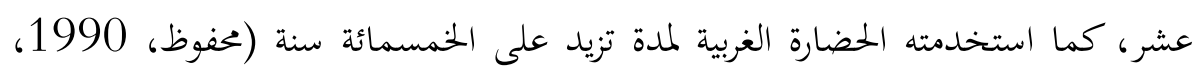

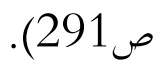

و(ابن النفيس)، الذي اهتم بدراسة هذا النوع من الأمراض، وتميزت دراسته

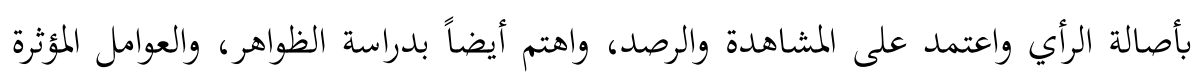

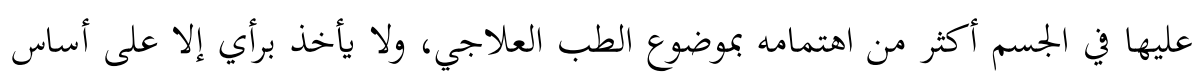

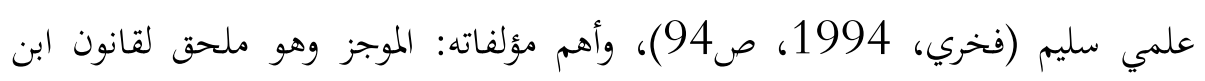
سينا، وشرح تشريح القانون (فخري، 1994، صخيمي، (95).

كما بحث "علي بن العباس" المعروف بابن المجوسي (384هـ/944م) عن مرض

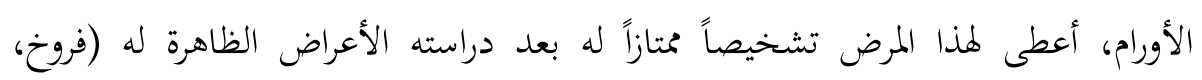

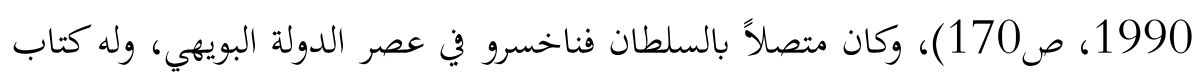
"المكي" والذي يقع في عشرين مقالة، ويتميز عن غيره من كتب الطب بالوضوح والدقة

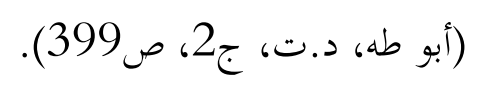


2.3 العوامل والأسباب المؤدية إلى انتشار الأورام في رأي الأطباء المسلمين

1.2 .3

قبل أن يعرف العالم العوامل المسببة، أو المساعدة في حدوث الأورام "السرطان"

بأكثر من أربعة عشر قرناً ولمماية المجتمع من ويلات هذا المرض الخبيث، فهى الإسلام عن لهن

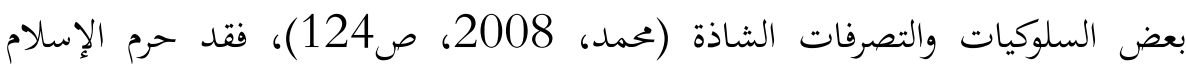

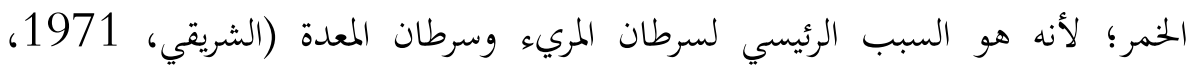

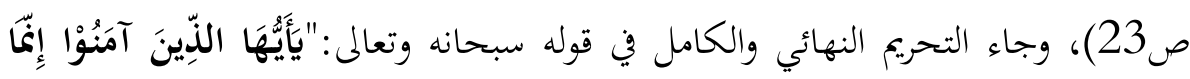

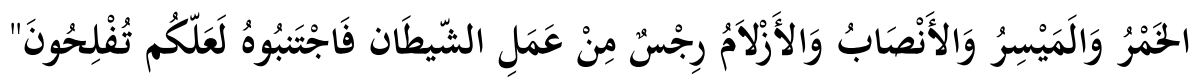
(سورة المائدة، الآية 92)، كما حرم أكل لحم الحنزير الذي أثبتت الأبحاث الحديثة بأن الإفراط في تناول الدهون الحيوانية التي مصدرها لحم الحنزير يؤدي إلى الإصابة بالسرطان

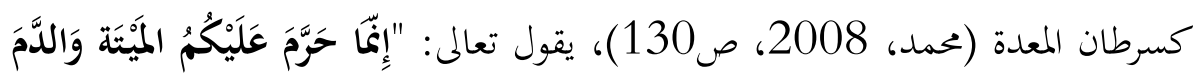
وَلَحَمَ المَنْنِيَر" (سورة البقرة ، الآية 172).

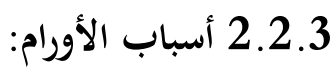

- يقول بعض الأطباء المسلمين إن كثرة الجلوس في الشمس (الشريقي، 1971، ص28)،

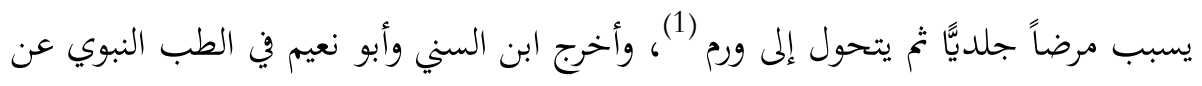

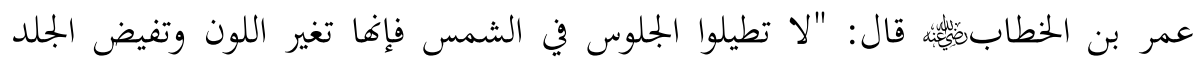

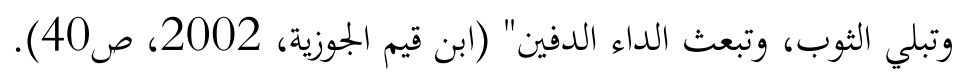

(1) أثبت بعض الدراسات الحدينة أن أشعة الشمس تسبب في سرطان الجلد. 
- الإسراف في الأكل والشراب يؤدي إلى فقدان الخلايا مواصفاها الطبيعية فتسبب الأورام (بجلة الفيصل، 2008، ص208)، وذلك على حسب ما أورده الزهراوي في كتابه (1)، وقد حث الإسلام على الاعتدال في الطعام والشراب وعلى العناية في تناولما ومراعاة آدابمما

$$
\text { (فروخ، 1991، ص140). (فرن) }
$$

- وقد ذكر الرازي أن العدوى الوراثية هي سبب انتشار المرض، ولم تكتمل الآراء التي يوردها نتيجة لجهوده الخاصة فقط، وإنما نجد حين يتحدث عن مرض من الأمراض يقوم أولاً بجمع الآراء التي ذكرت عن المرض، ثم يبدأ بعد ذلك في عرض رأيه والتجارب التي أجراها والمشاهدات التي توصل إليها كنتيجة عملية للتشخيص والعلاج (محمد، 1991،

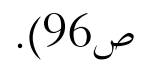

- وللمناخ والبيئة دور في انتشار الأورام وذلك عندما يحل الجفاف والقحط في منطقة ما (بجلة الفيصل، 2008، ص24)، فيفقد الإنسان تعادل المواد الكيميائية في جسمه، يقول جابر بن حيان: "أن تعادل المواد الكيميائية في جسم الإنسان يعتبر حصانة من الأمراض فمتى حصل التعادل وجد الإنسان مناعة قوية ضد الأمراض الخطيرة مثل البرص، والجذام، والأورام. وغيرها" (حلاق،1989، ص1901). ومن حكمة الله عز وجل أن فرض الوضوء للصلاة، فقد أثبت العلم الحديث أن الوضوء يقلل من حدوث الأورام السرطانية التي تسببها المواد الكيميائية (محمد، 2008، ص115)؛ لأن الوضوء خمس مرات في اليوم يكفل إزالة المواد من فوق سطح الجلد (ابن قيم الجوزية، 2002، ص 149).

(1) فقد اثبت الدراسات الحديثة أن الإفراط في الطعام فوق حد جسم الإنسان تسبب ثمول في خلايا الجسم ومن تم تتحول إلى أورام. 


\section{3 طرق علاجه في الحضارة الإسلامية.}

اختلفت طرق علاج الأورام من منطقة إلى أخرى، فالبعض منها اعتمد على

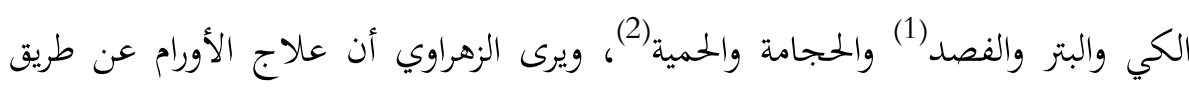

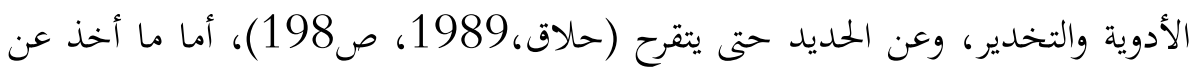
الطب الهندي في علاج الأورام في فترة الحضارة الإسلامية هو استخدام الأعشاب والكي (محمد، 2008، ص154)، والطب الصيني اعتمد على الأدوية النباتية والكي، وحين

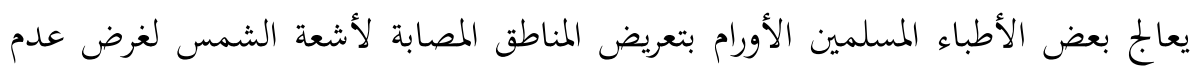

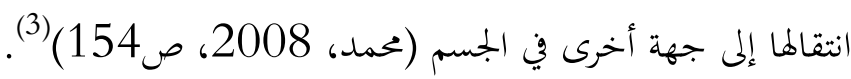

وأما ما جاء في كتاب (علي بن عباس الزهراوي) الذي تكلم فيه عن حفظ الصحة، والتي هي أهم وسائل العلاج لهذا المرض حيث أكد على ممارسة الرياضة لحفظ

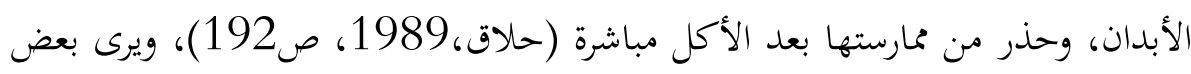

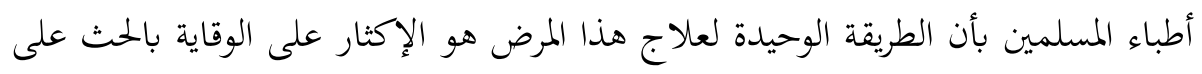

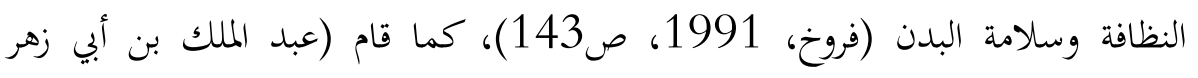
الملقب بأبي مروان) بدراسة مفصلة عن مرض السرطان في المعدة والبلعوم، أدهشت علماء وأطباء العصر الحديث، وقد استطاع أطباء مسلمون بتنظيف المعدة التي تعرضت للألأورام

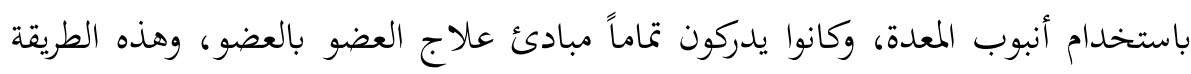
في المعالجة التي نسبت في أوائل القرن العشرين إلى (براون سيبكوارد) كان الأطباء المسلمون

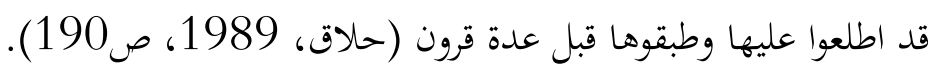

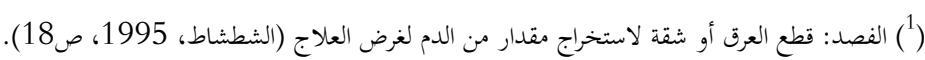

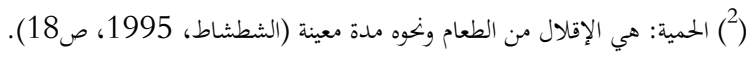
(3) وهي أساس تقنيات التصوير الإشعاعي حديثاً. 
وهناك فئة ترى أن سبب هذا المرض من السحر والشعودة، ولذذا كانت تستخدم بعض العقاقير وأدوية نباتية أو معدنية (الشطشاط، 1995، ص27)، وكذلك استخدمت هذه الفئة الخرزات والأحجار، وذلك للتخلص من بعض الآلام والوقاية من الإصابة بالعين والآفات (النجار، 1989، ص53). ثم ظهرت جراحة الأورام وبلغت ذروتما في الحضارة الإسلامية، ويعتبر الزهراوي أشهر جراحي المسلمين حيث اخترع كثيراً من الآلات الجراحية ورسمها في كتابه، وقال عنه العالم الطبيعي (هللر): كان هو المصدر العام لجميع من ظهر من الجراحين (الرافعي، 1988، ص292)، وهو من أعظم أطباء المسلمين الذين عرفوا طريقة استئصال الورم بالجراحة ( كفاجي، 1970، ص59). أما (عباس الأهوازي) فقد اهتم أيضاً بطب الجراحة، ووصف علاج قطع الشريان والورم المسمى (انورسما Aneurysm)، إلا أن الكي بالنار قد احتل الصدارة عند بعض الاطباء، مع وصف الأعشاب والأدوية النباتية (الشريقي، 1971، ص24). واستخدم الاطباء في العصر العباسي مواد لكي تجري الجراحة وهي المخدرات كالحشيش والأفيون، وأما الآلات الجراحية التي استعملها الأطباء في هذا العصر فأشهرها: (المحك) ويستعمل لحك الأجفان، (والمثقب)، للثقب،

$$
\text { (والمشرط) لشق الأورام (طوقان، د.ت، ص25). }
$$

وأكد (ابن حيان) أن التركيبات الكيميائية الصحيحة هي التي تمنع الأمراض الخطيرة وتساعد الجسم على المقاومة (فخري، 1994، ص97). أما (الرازي) فيرى بأن التغذية الصحيحة هي السبب في الوقاية من أي مرض، وأن تناول الإنسان اللحم الذي يعتبر من أهم أنواع الغذاء وأوفرها نفعاً، وهو أمر قد أكده علم التغذية الحديث (المذذوب، .) (168) 1976، (196) 


\section{4. الخاتمة:}

توصلت الدراسة عن الطب وجراحة الأورام عند المسلمين للنتائج التالية:

- أوضحت الدراسة أن مصطلح الأورام قديم لم يظهر حديثاً فقد استعمله الأطباء في فترة الحضارة الإسلامية تحديداً في القرن الرابع الهجري.

- بيّنت الدراسة أن الورم الذي لا ينتشر؛ سمّى بالورم الحميدي، أما السرطان فهو الذي ينتشر بسرعة في الجسم، وكان اكتشافه وتشخيصه في فترة ما قبل الميلاد.

- - وأظهرت الدراسة أن ما جاء من النصائح الطبية لا يزال معمولاً بها في الوقت الحاضر، وهي التي أخذها المسلمون عن الطب النبوي اقتداء بالرسول الكريمئسئوبالنسبة لعلاج الأورام أوضحت الدراسة أفها علاجات لا يزال يعمل .هما في هذا العصر فمثلاً: الكي والتعرض لأشعة الشمس؛ فهو حالياً ما يشبه التصوير الإشعاعي أو استخدام الليزر، والتركيبات الكيميائية حالياً ما يعرف بالكيمياوي، والفصد حالياً ما يشبه استئصال الجزء المتورم. - - وأظهرت الدراسة أن جراحة واستئصال الأورام بلغت ذروما في الحضارة الإسلامية وظهر العديد من الجراحيين المسلمين، وابتكروا كثيراً من الآلات الجراحية، وكانوا هم المصدر الأساسي لجميع من ظهر من الجراحين من بعدهم. 


\section{المراجع}

القرآن الكريم: برواية قالون عن نافع. ابن أبي أصيبعة، موفق الدين أبو العباس (1981). عيون الأنباء في طبقات الأطباء. القاهرة: دار الثقافة.

ابن قيم الجوزية، (د.ت). الطب النبوي. تحقيق: عبد المجيد، بيروت: دار المعرفة.

الأندلسي، صاعد أبو القاسم أحمد (1985). طبقات الأمم، تحقيق: حياة بو علوان بيروت: دار الطباعة.

$$
\text { إبراهيم، أحمد (2018) كيف تطور الطب في الإسلام. }
$$

History, https://www.zliyazeera.het(2018-2-23)

أحمد، أحمد عبد الرزاق (1991). الحضارة الإسلامية في العصور الوسطى. القاهرة: دار الفكر العربي.

جواد، على (1971). المفصل في تاريخ العبب قبل الإسلام، ج8، بغداد: مكتبة النهضة. حتى، فليب (1986). تاريخ العرب. بيروت: د.ن. حسن، حسن إبراهيم (1957). تاريخ الإسلام. ج1، ط4، القاهرة: د.ن. حلاق، حسان (1989). دراسات في تاريخ الحضارة الإسلامية. بيروت: دار النهضة العربية 
حلاق، حسان، وآخرون (1991). مقدمة في تاريخ العرب السياسي والاقتصادي والاجتماعي والديني والعلمي. بيروت: المحروسة للطباعة والنشر. الخارن، وليم (1992). الحضارة العباسية. ط2، د.م: دار المشرق. الخربوطلي، علي حسني (د.ت). الحضارة العربية الإسلامية. القاهرة: مكتبة الخانجي. الرافعي، مصطفى (1988). حضارة العرب. ط4، بيروت: الشركة العالمية للكتاب. سليمان، عباس (1990). دراسات في تاريخ العلوم عند العرب. بيروت: دار النهضة. سيف الدين، إبراهيم نمير (1991). مصر في العصور القديمة. القاهرة: مكتبة مدبولي. الشريقي، إبراهيم (1971). التاريخ الإسلامي خلال أربعة عشر قرنًا-مند العهد النبوي حتى العصر الحاضر. ط4، د.م.

الشطشاط، علي (1995). تاريخ الجراحة في الطب العربي. بنغازي: جامعة قاريونس. الشطي، شوكت موفق (1956). تاريخ الطب القديم. دمشق: د.ن. طوفان، قدري حافظ (د.ت). العلوم عند العرب. القاهرة: دار إقرأ. الفاضل، عمر (1989). الطب الإسلامي عبر القرون. الرياض: دار الشواف للطباعة. فخري، نجاة وآخرون (1994). عباقرة من التاريخ. بيروت: مكتبة بيسان. فروخ، عمر (1981). العرب في حضارتم وثقافتهم. ط2، بيروت: دار العلم للملايين.

$$
\text { كروخ، عمر (1990). تاريخ العلوم عند العرب. بيروت دار النهضة. }
$$


كفاجي، محمد عبد السلام (1971). الحضارة العربية ومعوماتها العامة. بيروت: دار النهضة العربية.

المجذوب، عبد العزيز (1976). الرازي من خلال تفسيره. طرابلس: الدار العربية للكتاب. بجلة الفيصل (2008) مركز الفيصل للدراسات العلمية. الكويت ع21. محفوظ، عبد الكريم (1990). عبقرية الحضارة العربية منبع النهضة / لأوروبية. بنغازي: دار

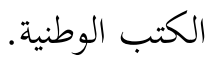

محمد، ماهر عبد القادر (1991). دراسات وشخصيات في تاريخ الطب العربي. الاسكندرية: دار المعرفة الجامعية.

محمد، محمود الحاج قاسم (2008). الأورام والسرطان وعلاجه في الطب العربي

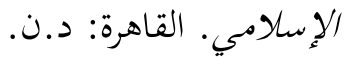

مرحبا، محمد عبد الرحمن (1988). الجامع في تاريخ العلوم عند العبب. ط2، بيروت: منشورات عويدات.

مظهر، جلال (د.ت). حضارة الإسلام وأثرها في الترقي العالمي. القاهرة: مكتبة الخانجي. موازي، حميد وآخرون (1974). قراءات في تاريخ العلوم عند العبب. الموصل: دار الكتب للطباعة والنشر.

$$
\text { النجار، عمار (1987). في تاريخ الطب في الدولة الإسلامي. القاهرة: د.ن. }
$$

